\title{
Article \\ Development of an Estimation Formula to Evaluate Mission Motion Suitability of Military Jackets
}

\author{
Hee-Eun Choi * and Jung-Il Jun
}

check for updates

Citation: Choi, H.-E.; Jun, J.-I. Development of an Estimation Formula to Evaluate Mission Motion Suitability of Military Jackets. Appl. Sci. 2021, 11, 9129. https://doi.org /10.3390/app11199129

Academic Editor: Jesús García Pallarés

Received: 24 August 2021

Accepted: 28 September 2021

Published: 30 September 2021

Publisher's Note: MDPI stays neutral with regard to jurisdictional claims in published maps and institutional affiliations.

Copyright: (c) 2021 by the authors. Licensee MDPI, Basel, Switzerland. This article is an open access article distributed under the terms and conditions of the Creative Commons Attribution (CC BY) license (https:/ / creativecommons.org/licenses/by/ $4.0 /)$.
University-Industry Collaboration Foundation, Dong Seoul University, Seongnam 13117, Korea; junjungill@hanmail.net

* Correspondence: bthexpert@snu.ac.kr; Tel.: +82-(31)-607-3100

Abstract: We developed an estimation formula for mission motion suitability evaluation based on the general motion protocol to evaluate the motion suitability of a tracked vehicle crew jacket. Motion suitability evaluation was conducted for the 9 general motions and 12 mission motions among 27 tracked vehicle crew members who wore a tracked vehicle crew jacket. We conducted correlation and factor analyses on motions to extract the main mission motions, and a multiple regression analysis was performed on major mission motions using general motions as independent variables. As a result, two mission behavior factors related to ammunition stowing and boarding/entry were extracted. We selected ammunition stowing I and the boarding motion, which has the highest factor load in each factor and the highest explanatory power $\left(\mathrm{R}^{2}\right)$ of the estimation formula. Regression equations for ammunition stowing consisting of five general motions $(p<0.001)$ and for boarding motion $(p<0.01)$ consisting of one general motion could be obtained. In conclusion, the estimation formula for mission motion suitability using general motion is beneficial for enhancing the effectiveness of the evaluation of military jackets for tracked vehicle crews.

Keywords: estimation formula; mission motion suitability; military jacket; mission motion protocol

\section{Introduction}

The armed fighting vehicle (AFV) [1] is a tracked combat vehicle and a type of weapon system having specific functions in battle. In particular, the main battle tank (MBT) is a symbol of armored army forces and is designed with consideration for firepower, mobility, and protection [2]. The members of the main battle tank vary depending on the model, but third-generation main battle tanks in China, Russia, France, the United States, and Germany mainly consist of three or four crew members (commander, gunner, driver, and loader) [3]. The K1-series, Republic Of Korea's third-generation main battle tanks also have four crew members [4]. The mission efficiency of crew members regarding the operation of tracked vehicles has a significant impact on combat power [1]. Each crew member plays a different role, but they also perform common missions such as ammunition stowing, which is a high-intensity task [5]. However, the interior of the tracked vehicle is very narrow, and seats and protruding structures that are not ergonomic in design cause musculoskeletal discomfort for the tracked vehicle crew while performing missions [6-8]. Moreover, the vehicle crew reported discomfort while performing the mission motion because of their current uniform [9-11]. Uniforms worn during the mission should not interfere with performance. Therefore, the tracked vehicle crew's uniforms should be developed considering mission motion suitability [11].

Previous studies on the development of military uniforms have evaluated the motion suitability of clothing using general motion and mission motion [11-16]. The motion suitability of protective clothing mainly deals with the usability of the joints from an anatomical point of view [17]. All motions of joints can be described as flexion, extension, adduction, abduction, rotation, pronation, or supination $[18,19]$, and general motion for evaluating the motion suitability of the jackets includes the usability of joints of the cervical column 
(neck), lumbar vertebrae (trunk), shoulder, and elbow [11-15]. In particular, the shoulder joint is the joint with maximum movement among all the joints of the human body [19]; the usability of the shoulder joint is important in judging functional clothing [12]. On the contrary, the mission motion suitability evaluation includes consecutive motions; a number of studies have developed motion protocols to evaluate garment comfort and to test performance according to the type of clothing and the wearer's mission. A firefighter simulation protocol was developed to evaluate refighting operations [20]. Another study developed five simulation operation protocols to develop the ROK Navy summer uniform [21]. In addition, a training scenario assuming chemical accidents and terrorism through the analysis of the field crew activity was conceptualized [22]. Military combat uniforms were evaluated using the main combat training motions performed in combat training [14]. However, most of the training of a special group of tracked vehicle crew members is conducted inside and outside of the tracked vehicle, and their respective duties often require them to perform motions that differ from combat training motions usually performed by ordinary soldiers. Therefore, a mission motion protocol was developed for the evaluation of the tracked vehicle crew jacket [11].

However, because the clothing development goes through an iterative design process from preliminary investigation to the final product, following the mission motion protocol, every time an intermediate evaluation of a sample is conducted, it may be seen as a waste of time and materials. In particular, it is impossible to completely reproduce the internal and external environments of a tracked vehicle in order to evaluate the military uniforms of the tracked vehicle crew, and evaluation is limited due to the nature of military security. Therefore, developing an estimation formula that can evaluate the motion suitability during clothing development may shorten the time necessary for the clothing development process and improve the efficiency of development.

Therefore, this paper proposes an estimation formula for evaluating the mission motion suitability of a tracked vehicle crew jacket based on data from easily collected general motions for efficiency in product development as a surrogate measure.

\section{Methods}

\subsection{Collecting Data for Developing an Estimation Formula}

We conducted motion suitability evaluation on 27 tracked vehicle crew members on active duty under $\mathrm{K} 1$ to collect data for developing an estimation formula. For verification, 10 crews who participated in the same experiment performed additional experiments in the same way.

They performed motion suitability evaluation wearing combat uniforms for tracked vehicle crew inside a tracked vehicle crew jacket and a military winter jacket. Figure 1 shows a tracked vehicle crew jacket (left) and a military winter jacket (right). A military winter jacket is mainly worn inside the tracked vehicle instead of the tracked vehicle crew jacket, which was used to verify the development of an estimation formula.

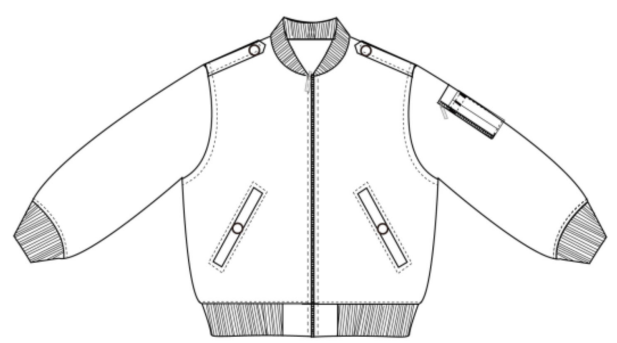

(a)

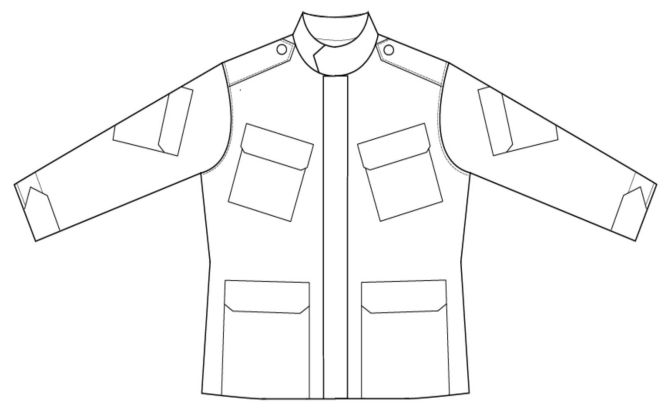

(b)

Figure 1. Jackets worn inside tracked vehicles: (a) Korean tracked vehicle jacket and (b) Korean military winter jacket. 
The general motions used to evaluate motion suitability were taken from a previous study that evaluated the military winter jacket [11-16]. These general motions include the joints of the neck, shoulder, elbow, and trunk. Table 1 lists the nine general motions. They performed general motions while judging the usability of the joints in a standing position, and mission tools were excluded, such as heavy ammunition and pistols, which could affect the load so that the subjects could focus on the evaluation of clothing and obtain more accurate results.

Table 1. General motions for motion suitability evaluation.

\begin{tabular}{|c|c|c|c|c|c|c|c|c|c|}
\hline No. & 1 & 2 & 3 & 4 & 5 & 6 & 7 & 8 & 9 \\
\hline General & $\begin{array}{l}\text { Stand } \\
\text { erect }\end{array}$ & $\begin{array}{c}\text { Neck } \\
\text { rotation }\end{array}$ & $\begin{array}{c}\text { Shoulder } \\
\text { flexion } \\
90^{\circ}\end{array}$ & $\begin{array}{c}\text { Shoulder } \\
\text { flexion } \\
180^{\circ}\end{array}$ & $\begin{array}{l}\text { Horizontal } \\
\text { shoul- } \\
\text { der } \\
\text { abduction } \\
90^{\circ}\end{array}$ & $\begin{array}{l}\text { Elbow } \\
\text { flexion }\end{array}$ & $\begin{array}{l}\text { Shoulder } \\
\text { exten- } \\
\text { sion }\end{array}$ & $\begin{array}{l}\text { Horizontal } \\
\text { shoul- } \\
\text { der } \\
\text { adduction } \\
90^{\circ}\end{array}$ & $\begin{array}{l}\text { Trunk } \\
\text { flexion }\end{array}$ \\
\hline motions & 9 & या & 우 & 0 & 오 & $O_{m}$ & $r$ & V & \\
\hline
\end{tabular}

Further, mission motions used to evaluate motion suitability were based on the mission motion protocol for a tracked vehicle crew, which was developed through a focused group interview (FGI) with 16 crews (seven commanders, three gunners, four drivers, and two loaders). Table 2 shows the common mission motions and individual mission motions of the tracked vehicle crew members [11]. Common mission motions include vehicle boarding, entry, ammunition carrying, ammunition stowing, escaping, and getting off. Individual mission motions include ammunition loading, sitting activity, driving, and maintenance.

Table 2. Mission motions for motion suitability evaluation.

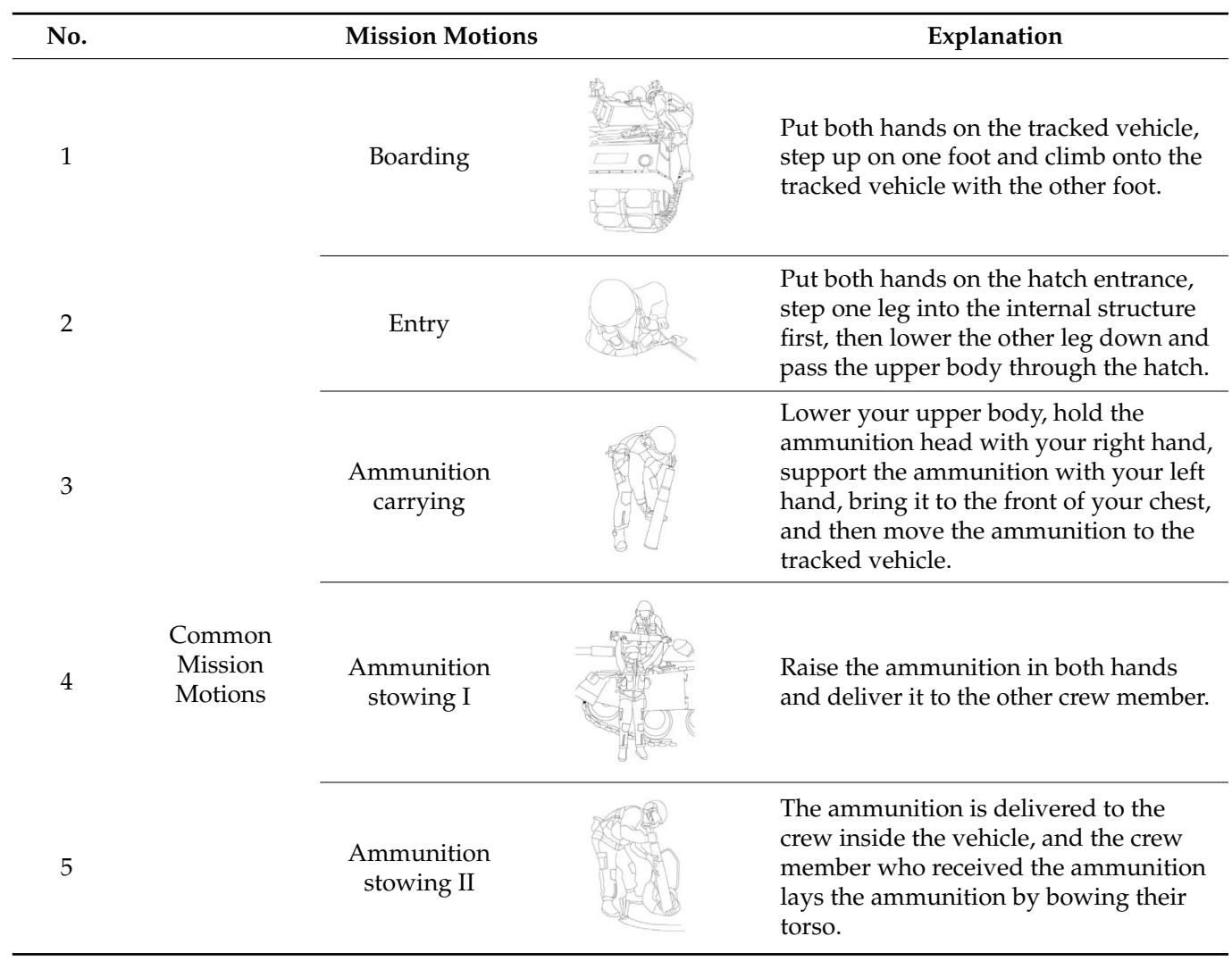


Table 2. Cont.

\begin{tabular}{|c|c|c|c|}
\hline No. & & Mission Motions & Explanation \\
\hline 6 & & Escaping & $\begin{array}{l}\text { Raise both arms above your head, place } \\
\text { both hands at the hatch entrance, and } \\
\text { then pass the hatch through the head, } \\
\text { torso, and legs in this order. }\end{array}$ \\
\hline 7 & & Getting off & $\begin{array}{l}\text { Use a ladder to descend, or sit in a } \\
\text { tracked vehicle and jump. }\end{array}$ \\
\hline 8 & $\begin{array}{l}\text { Individual } \\
\text { Mission } \\
\text { Motions }\end{array}$ & $\begin{array}{l}\text { Ammunition } \\
\text { loading }\end{array}$ & $\begin{array}{l}\text { Hold the ammunition loaded inside } \\
\text { with both hands up to the chest } \\
\text { position, pull the right shoulder back, } \\
\text { then inject the ammunition by pushing } \\
\text { the shoulder forward. }\end{array}$ \\
\hline 9 & & $\begin{array}{l}\text { Sitting } \\
\text { activity }\end{array}$ & $\begin{array}{l}\text { The gunner looks at the sight for a shot. } \\
\text { The commander looks closely at the } \\
\text { tracked vehicle operation and shooting } \\
\text { instructions. }\end{array}$ \\
\hline 10 & $\begin{array}{l}\text { Individual } \\
\text { Mission }\end{array}$ & Driving I & $\begin{array}{l}\text { The driver sits in the cockpit, holds the } \\
\text { steering wheel with both hands, and } \\
\text { moves his shoulders back and forth } \\
\text { while driving. }\end{array}$ \\
\hline 11 & Motio & Driving II & $\begin{array}{l}\text { Tilt the cockpit back, drive with } \\
\text { shoulders back and forth extending } \\
\text { arms. }\end{array}$ \\
\hline 12 & & Maintenance & $\begin{array}{l}\text { The driver performs maintenance in the } \\
\text { cockpit or outside the tracked vehicle } \\
\text { with both hands facing down and } \\
\text { bending at the waist. }\end{array}$ \\
\hline
\end{tabular}

According to the mission motion protocol for a tracked vehicle crew, the three crew members (A, B, and C) formed a team and performed the procedures three times in a tracked vehicle environment. For common mission motions such as ammunition carrying and ammunition loading, in order to maintain the same flow of motion as when performing an actual mission, three crew members proceeded according to their respective duties, but changed the missions every cycle so that all missions could be performed. The series of mission motion protocols are presented in Table 3 [11].

Table 3. Mission motion protocol for motion suitability evaluation.

\begin{tabular}{ccl}
\hline No. & Mission Motions & \multicolumn{1}{c}{ Explanation } \\
\hline 1 & $\begin{array}{c}\text { Ammunition } \\
\text { carrying(Crews A, B, C) }\end{array}$ & $\begin{array}{l}\text { Crews A, B, and C move to the tracked vehicle with the } \\
\text { ammunition on the floor (10 m). }\end{array}$ \\
\hline 2 & $\begin{array}{c}\text { Boarding } \\
(\text { Crews A, B) }\end{array}$ & $\begin{array}{c}\text { Crews A and B put one foot on the tracked vehicle and } \\
\text { get on the tracked vehicle with the other. }\end{array}$ \\
\hline 3 & Entry (Crew A) & Crew A opens the loader's hatch and goes inside. \\
\hline 5 & $\begin{array}{c}\text { Ammunition stowing I } \\
(\text { Crews B, C) }\end{array}$ & $\begin{array}{l}\text { Crew C raises their arms to Crew B on top of the tracked } \\
\text { vehicle and raises the ammunition. }\end{array}$ \\
\hline \multirow{2}{*}{5} & $\begin{array}{c}\text { Ammunition stowing II } \\
\text { (Crews A, B) }\end{array}$ & $\begin{array}{l}\text { Crew B receives the ammunition and delivers it to Crew } \\
\text { A inside the tracked vehicle. }\end{array}$ \\
\hline
\end{tabular}


Table 3. Cont.

\begin{tabular}{ccl}
\hline No. & Mission Motions & \multicolumn{1}{c}{ Explanation } \\
\hline 6 & $\begin{array}{c}\text { Boarding } \\
\text { (Crews B, C }\end{array}$ & Crew B and C open the commander's hatch and enter. \\
\hline 7 & Sitting activity & $\begin{array}{l}\text { After taking a seat, prepare to shoot while looking at the } \\
\text { periscope. }\end{array}$ \\
\hline 8 & Ammunition loading & Load ammunition manually. \\
\hline 9 & Escaping & Open the commander's hatch and step outside. \\
\hline 10 & Entry & Open the driver's hatch and go inside. \\
\hline 12 & Driving I & Perform normal driving. \\
\hline 14 & Driving II & $\begin{array}{l}\text { Close the hatch, lie down at an angle, and perform a } \\
\text { closed control operation. }\end{array}$ \\
\hline 15 & Maintenance & $\begin{array}{l}\text { Sit in the cockpit seat, lean forward, and perform } \\
\text { maintenance. }\end{array}$ \\
\hline
\end{tabular}

The evaluation scale for general motion and mission motion suitability consists of a 7-point Likert scale $[11,13]$ with 1 point meaning very uncomfortable, 2 points meaning uncomfortable, 3 points meaning slightly uncomfortable, 4 points meaning moderate, 5 points meaning moderately comfortable, and 6 and 7 points meaning comfortable and very comfortable, respectively.

\subsection{Data Analysis for Developing an Estimation Formula}

Correlation and factor analyses of mission motions were conducted to identify correlations in mission motions and to extract the main mission motions. A correlation analysis between general motion and mission motion was also performed to select the independent variables used in the estimation formula. A multiple regression analysis was used to develop an estimation formula for motion suitability evaluation based on the correlation between general motion factors, which could be used instead of the mission motion suitability evaluation.

Data analysis was performed using SPSS 28.0 ver. The mean scores $(\mathrm{m})$ and standard deviation (SD) of the suitability evaluation of each motion were included in the results. As a result of Shapiro-Wilk test, the $p$-value is higher than 0.05 to prove a normal distribution at the level of $p<0.05$; therefore, in order to determine validity, a paired $t$-test was conducted between the estimation formula value and the real mission motion suitability score for the tracked vehicle crew jacket and the military winter jacket. In addition, to verify the reliability of the repeated measurement of the estimation formula, the formula was applied to the general motion evaluation results of 10 study subjects who wore the tracked vehicle crew jacket, and the results were compared.

\section{Results}

\subsection{The Relationship between the Mission Motions of the Tracked Vehicle Crew}

In the correlation analysis of mission motion (Table 4), it was found that each motion was related to other motions. There was a highly positive and significant correlation between boarding and entry $(r=0.833, p<0.05)$. There was also a positive correlation between boarding and its opposite actions, such as escaping $(p<0.01)$ and getting off $(p<0.01)$, and it was highly and positively correlated with sitting activity $(p<0.01)$, driving I $(p<0.01)$, driving II $(p<0.001)$, and maintenance $(p<0.05)$, including bending motion in a confined space. Ammunition was positively correlated $(p<0.05)$ with the ammunition stowing II because one of the two people moved from the deck of a tracked vehicle with 
ammunition; however, it was not significantly correlated with most mission motions. In the case of ammunition stowing, one of the two people raised the ammunition while the other had to sit or bend to receive the ammunition; therefore, this had a positive correlation $(p<0.05)$ with sitting activity and maintenance. There was also a very high positive correlation between ammunition stowing I and II ( $\mathrm{r}=0.829, p<0.01)$. The rest of the motions were not significantly correlated with ammunition loading, except for the escape motion $(p<0.05)$, wherein the shoulder joint was used to raise the upper body through the hatch. Sitting activity showed a high positive correlation with driving I and maintenance in an enclosed space $(p<0.001)$.

Table 4. Correlation results between mission motions $(n=27)$.

\begin{tabular}{|c|c|c|c|c|c|c|c|c|c|c|c|c|}
\hline & M1 & M2 & M3 & M4 & M5 & M6 & M7 & M8 & M9 & M10 & M11 & M12 \\
\hline M1 & 1 & $0.833^{* *}$ & 0.066 & 0.401 & 0.175 & 0.483 & $0.751 * *$ & 0.732 ** & $0.829 * *$ & $0.818^{* *}$ & $0.873^{* * *}$ & $0.661^{*}$ \\
\hline M2 & $0.833 * *$ & 1 & 0.197 & 0.172 & -0.117 & 0.414 & $0.635 *$ & 0.732 ** & $0.638 *$ & $0.764^{* *}$ & $0.818^{* *}$ & 0.472 \\
\hline M3 & 0.066 & 0.197 & 1 & 0.536 & 0.604 * & 0.095 & 0.500 & 0.402 & 0.238 & 0.236 & 0.279 & 0.302 \\
\hline M4 & 0.401 & 0.172 & 0.536 & 1 & $0.829^{* *}$ & 0.225 & $0.675^{*}$ & 0.226 & 0.537 & 0.488 & 0.525 & $0.653 *$ \\
\hline M5 & 0.175 & -0.117 & 0.604 * & $0.829 * *$ & 1 & 0.254 & 0.547 & 0.241 & 0.503 & 0.345 & 0.345 & $0.609 *$ \\
\hline M6 & 0.483 & 0.414 & 0.095 & 0.225 & 0.254 & 1 & 0.382 & 0.670 & 0.607 & 0.452 & 0.632 & 0.479 \\
\hline M7 & $0.751 * *$ & $0.635^{*}$ & 0.500 & $0.675^{*}$ & 0.547 & 0.382 & 1 & 0.550 & $0.817^{* *}$ & $0.869^{* * *}$ & $0.832^{* *}$ & $0.851^{* * *}$ \\
\hline M8 & $0.732 * *$ & $0.732^{* *}$ & 0.402 & 0.226 & 0.241 & $0.670 *$ & 0.550 & 1 & $0.689 *$ & $0.619 *$ & $0.699 *$ & 0.419 \\
\hline M9 & $0.829 * *$ & $0.638 *$ & 0.238 & 0.537 & 0.503 & 0.607 & $0.817^{* *}$ & $0.689 *$ & 1 & 0.793 & 0.897 & 0.876 \\
\hline M10 & $0.818^{* *}$ & $0.764^{* *}$ & 0.236 & 0.488 & 0.345 & 0.452 & $0.869^{* * *}$ & $0.619 *$ & 0.793 & 1 & 0.875 & 0.773 \\
\hline M11 & $0.873^{* * *}$ & $0.818^{* *}$ & 0.279 & 0.525 & 0.345 & 0.632 & $0.832 * *$ & 0.699 * & 0.897 & 0.875 & 1 & 0.804 \\
\hline M12 & 0.661 * & 0.472 & 0.302 & 0.653 * & $0.609 *$ & 0.479 & $0.851^{* * *}$ & 0.419 & 0.876 & 0.773 & 0.804 & 1 \\
\hline
\end{tabular}

M1: boarding; M2: entry; M3: ammunition carrying; M4: ammunition stowing I; M5: ammunition stowing II; M6: ammunition loading; M7: sitting activity; M8: escaping; M9: getting off; M10: driving I; M11: driving II; M12: maintenance. Values are correlation coefficients. $p^{*}<0.05, p^{* *}<0.01$, $p^{* * *}<0.001$.

\subsection{Selection of the Main Mission Motions of the Tracked Vehicle Crew}

A factor analysis was performed on a total of 12 mission motions to extract the main mission actions. After eliminating multicollinearity among driving I, driving II, escaping, seating activity, getting off, and maintenance, the factor analysis was repeated, and a total of two factors were identified. Kaiser-Meyer-Olkin (KMO) was 0.580, Bartlett was at the $p<0.001$ level, and the cumulative contribution of total common factor variance was $95.01 \%$. Table 5 shows factor analysis results of main mission motions of a tracked vehicle crew.

Factor 1 refers to the motions associated with ammunition stowing and has an explanatory power of $48.47 \%$ for the mission motions of the tracked vehicle crew, with an internal consistency of 0.956 . Factor 1 refers to the motions associated with delivering ammunition to the crew on the tracked vehicle and stowing it inside the tracked vehicle; therefore, it involves all motions related to the ammunition.

Factor 2 refers to the motions associated with boarding and entering tracked vehicles and has an explanatory power of $46.54 \%$ for the mission motions of tracked vehicle crews, with an internal consistency of 0.922 . Motions belonging to Factor 2 may be referred to as mission motions, including the motion of bending the body to get on the vehicle and enter the interior.

In summary, the main task actions of the tracked vehicle crew can be divided into motions related to the loading of ammunition (Factor 1) and the action of boarding and entering the vehicle (Factor 2).

Table 5. Factor analysis results of main mission motions of a tracked vehicle crew $(n=27)$.

\begin{tabular}{|c|c|c|c|c|}
\hline \multirow[b]{2}{*}{ Motion } & \multicolumn{2}{|c|}{ Factor } & \multirow{2}{*}{$\begin{array}{c}\text { Common } \\
\text { Factor } \\
\text { Variance }\end{array}$} & \multirow[b]{2}{*}{ Cronbach's $\alpha$} \\
\hline & 1 & 2 & & \\
\hline Ammunition stowing I & 0.975 & 0.123 & \multirow[b]{2}{*}{48.47} & \multirow[b]{2}{*}{0.956} \\
\hline Ammunition stowing II & 0.945 & 0.260 & & \\
\hline Boarding & 0.148 & 0.962 & \multirow{2}{*}{46.54} & \multirow{2}{*}{0.922} \\
\hline Entry & 0.299 & 0.909 & & \\
\hline \multicolumn{3}{|c|}{ Total common factor variance (\%) } & \multicolumn{2}{|c|}{95.01} \\
\hline
\end{tabular}




\subsection{Development of Motion Suitability Evaluation Estimation Formula for Mission Motion}

Analysis of the correlation between mission motion and general motion (Table 6) revealed that there was a highly positive correlation between ammunition stowing I and ammunition stowing II with the stand erect, shoulder flexion $180^{\circ}$, shoulder extension, horizontal shoulder adduction $90^{\circ}$, and trunk flexion $(p<0.001)$. The reason ammunition stowing I and ammunition stowing II motion was positively correlated with the stand erect posture is that the collar and hem of the current tracked vehicle crew jacket are ribbed, so even in the stand erect posture, discomfort in the waist and neck influenced the evaluation. In addition, most of the ammunition loading motions showed a high correlation with the general motions related to the shoulder joint use motions, including the trunk flexion used in receiving ammunitions, as this is conducted in pairs.

Boarding and entry were correlated with the trunk flexion $(p<0.01)$ and shoulder flexion $180^{\circ}(p<0.05)$, but their correlations with shoulder flexion $180^{\circ}$ were as low as 0.35 and 0.33 , respectively.

Table 6. Correlation results between general motion and mission motion $(n=27)$.

\begin{tabular}{|c|c|c|c|c|}
\hline Motion & Boarding & Entry & $\begin{array}{l}\text { Ammunition } \\
\text { Stowing I }\end{array}$ & $\begin{array}{c}\text { Ammunition } \\
\text { Stowing II }\end{array}$ \\
\hline Stand Erect & 0.324 & 0.356 & $0.710^{* * *}$ & $0.644^{* * *}$ \\
\hline Neck rotation & 0.142 & 0.319 & 0.328 & 0.331 \\
\hline Shoulder flexion $90^{\circ}$ & 0.128 & 0.117 & 0.369 & 0.352 \\
\hline Shoulder flexion $180^{\circ}$ & $0.355 *$ & $0.326 *$ & $0.627^{* * *}$ & $0.641^{* * *}$ \\
\hline $\begin{array}{l}\text { Horizontal shoulder } \\
\text { abduction } 90^{\circ}\end{array}$ & -0.078 & 0.054 & 0.182 & 0.270 \\
\hline Elbow flexion & 0.243 & 0.169 & 0.282 & 0.230 \\
\hline Shoulder extension & 0.289 & 0.195 & $0.709^{* * *}$ & $0.805^{* * *}$ \\
\hline $\begin{array}{l}\text { Horizontal shoulder } \\
\text { adduction } 90^{\circ}\end{array}$ & 0.216 & 0.111 & $0.752^{* * *}$ & $0.693^{* * *}$ \\
\hline Trunk flexion & $0.521^{* *}$ & $0.462 * *$ & $0.573^{* *}$ & $0.548^{* *}$ \\
\hline
\end{tabular}

A multiple linear regression analysis was performed using general motions that showed a correlation of 0.4 or higher as the independent variable $(p<0.01, p<0.001)$, with respect to the main mission motions of the tracked vehicle crew, such as ammunition stowing I, ammunition stowing II, boarding, and entering.

Regression equations for ammunition stowing I and ammunition stowing II were derived using the stand erect, shoulder flexion $180^{\circ}$, shoulder extension, horizontal shoulder adduction $90^{\circ}$, and trunk flexion as independent variables for the regression analysis $(p<0.001)$. For boarding and entry, a regression equation was derived using trunk flexion as the independent variable $(p<0.01, p<0.05)$.

The equations for estimating the mission motion suitability of the tracked vehicle crew based on general motion are listed in Table 7.

Table 7. Estimation formula of main mission motion suitability $(n=27)$.

\begin{tabular}{cccccc}
\hline Motion & Equation & $\boldsymbol{R}$ & $\boldsymbol{R}^{2}$ & $S E E$ & $\boldsymbol{F}$ \\
\hline Ammunition & $\begin{array}{c}\mathrm{y}=-0.192+0.490 \mathrm{H}+ \\
0.356 \mathrm{~A}-0.406 \mathrm{D}+ \\
\text { stowing I }\end{array}$ & $0.170 \mathrm{G}+0.245 \mathrm{I}$ & & & \\
\hline Ammunition \\
stowing II & $\begin{array}{c}\mathrm{y}=0.170+0.243 \mathrm{H}+ \\
0.003 \mathrm{~A}-0.189 \mathrm{D}+ \\
0.582 \mathrm{G}+0.213 \mathrm{I}\end{array}$ & 0.848 & 0.718 & 0.652 & $13.017^{* * *}$ \\
\hline Boarding & $\mathrm{y}=1.283+0.519 \mathrm{I}$ & 0.521 & 0.271 & 0.242 & $9.313^{* * *}$ \\
\hline Entry & $\mathrm{y}=1.521+0.456 \mathrm{I}$ & 0.462 & 0.213 & 0.182 & $6.784^{*}$ \\
\hline
\end{tabular}

A, stand erect; D, shoulder flexion $180^{\circ} ; \mathrm{G}$, shoulder extension; H, horizontal shoulder adduction $90^{\circ}$; I, trunk flexion. $p^{*}<0.05, p^{* *}<0.01, p^{* * *}<0.001$. 
There was a significant positive correlation between ammunition stowing I and ammunition stowing II $(\mathrm{r}=0.829, p<0.01)$, as well as between boarding and entering $(\mathrm{r}=0.833$, $p<0.01)$, and each factor also had a high factor load $(0.975,0.962$, respectively). Moreover, the general motions used as independent variables were the same. Therefore, in this study, ammunition load I and boarding, the motions that had the highest factor load and the highest explanatory power $\left(R^{2}\right)$ in the estimation equation, were selected as representative motions of the tracked vehicle crew. The final estimation formula is as follows:

$$
\text { Ammunition Stowing I y }=-0.192+0.490 \mathrm{H}+0.356 \mathrm{~A}-0.406 \mathrm{D}+0.170 \mathrm{G}+0.245 \mathrm{I}
$$

$$
\text { Boarding } \mathrm{y}=1.283+0.519 \mathrm{I}
$$

A, stand erect; $D$, shoulder flexion $180^{\circ}$; $G$, shoulder extension; $H$, horizontal shoulder adduction $90^{\circ}$;

I, trunk flexion.

\subsection{Review of the Applicability of the Estimation Formula}

To confirm the validity of the developed estimation formula, we compared the results of the developed estimation formula when applied to a tracked vehicle jacket and a military winter jacket, which are mainly worn inside tracked vehicles, and the real evaluation score for the mission motion. (Table 8) shows no significant difference between the result of the developed equation and the real score at the level of $p<0.05$; therefore, the estimation formula is valid.

Table 8. Difference between values calculated of estimation formula and actual score $(n=10)$.

\begin{tabular}{ccccc}
\hline Military Uniform & Motion & $\begin{array}{c}\text { Developed } \\
\text { Equation }\end{array}$ & Real Score & $\boldsymbol{t}$-Value \\
\hline Tracked vehicle crew & Ammunition stowing I & $2.98 \pm 1.21$ & $3.20 \pm 1.32$ & 1.190 \\
jacket & Boarding & $2.63 \pm 0.66$ & $2.50 \pm 1.27$ & -0.424 \\
\hline \multirow{2}{*}{ Military winter jacket } & Ammunition stowing I & $3.38 \pm 0.63$ & $3.53 \pm 0.64$ & -1.121 \\
& Boarding & $2.85 \pm 0.52$ & $3.20 \pm 0.94$ & -2.367 \\
\hline Values are mean + SD. & & &
\end{tabular}

To verify the reliability of the repeated measurement of the estimation formula, the motion suitability results for the tracked vehicle crew jackets were applied to 10 soldiers who participated in the same experiment, and the results were compared (Table 9). There was no significant difference between the values calculated from the real evaluation scores evaluated in the first and second tests at the level of $p<0.05$; therefore, the repeated measurement of the estimation formula is reliable.

Table 9. Differences in values calculated of the estimation formula according to the test $(n=10)$.

\begin{tabular}{cccc}
\hline \multirow{2}{*}{ Motion } & \multicolumn{2}{c}{ Developed Equation } & \multirow{2}{*}{$\boldsymbol{t}$-Value } \\
\cline { 2 - 3 } & 1st Test & 2nd Test & \\
\hline Ammunition stowing I & $2.98 \pm 1.21$ & $2.95 \pm 1.07$ & 0.048 \\
Boarding & $2.63 \pm 0.66$ & $2.68 \pm 0.78$ & -0.136 \\
\hline
\end{tabular}

Values are mean \pm SD.

\section{Discussion}

The estimation formula of this study was developed based on the results of a motion suitability evaluation conducted on a tracked vehicle crew on active duty while performing a mission on an actual tracked vehicle. A total of nine general motions and 12 mission motions were included in the evaluation of the motion suitability of tracked vehicle crews [11]. All mission motions seemed to be different motions, but each of them was related to the other. The results of a correlation analysis conducted to investigate the characteristics 
and correlation of mission motion showed that boarding was highly correlated with other motions performed in a narrow space, such as seating, escaping, getting off, driving I, driving II, and maintenance $(p<0.05, p<0.01, p<0.001)$. Ammunition stowing I was highly related to seating and maintenance but showed the highest correlation with ammunition stowing II $(r=0.829)$. Ammunition loading motion carried out in pairs and motions, such as raising and receiving ammunitions, was performed simultaneously. Thus, these motions are correlated, including bending motions. These results suggest that actions can be grouped according to the similarity of the mission motion, and alternative evaluations may be conducted using representative motions that are highly correlated with other motions.

As a result of the factor analysis, two mission motion factors were extracted from a total of 12 mission motions used to evaluate the motion suitability of the tracked vehicle crew. These motions are related to ammunition loading using the shoulder and trunk joints (Factor 1), as well as boarding and entering the vehicle using the trunk joint (Factor 2). These two factors had high explanatory power, accounting for $95.01 \%$ of the mission motions. This means that the overall mission motion suitability evaluation for a tracked vehicle crew can be explained using these two factors as representative mission motions.

The estimation formula for the two factors developed in this study was based on the correlation between the mission motion and general motion. Ammunition stowing I and ammunition stowing II were highly positively correlated with the stand erect, shoulder flexion $180^{\circ}$, shoulder extension, horizontal shoulder adduction $90^{\circ}$, and trunk flexion $(p<0.001)$. Boarding and entry were correlated with trunk flexion $(p<0.01)$. This means that it is possible to evaluate the mission motion suitability of a tracked vehicle crew jacket through the performance of five general motions. Furthermore, ammunition stowing motion must be performed by at least three crew members in the mission protocol. However, when evaluating general motion, it can be performed individually and may be evaluated without time and space restrictions.

In this study, four equations were derived through a multiple linear regression analysis in which general motions with a correlation of 0.4 or more served as the independent variable $(p<0.01, p<0.001)$. However, we suggested a final estimation formula for ammunition stowing I and boarding motions, which had loading factors as high as 0.975 and 0.962 , respectively. Furthermore, we used the estimation equation with the highest explanatory power $\left(R^{2}\right)$ as a representative estimation formula for evaluating the mission motion suitability of the tracked vehicle crew jacket.

Furthermore, regarding the results of the final estimation formula application, there was no difference between the values calculated using the estimation formula and the real scores of mission suitability evaluation at the level of $p<0.05$. Moreover, repeated measures analysis showed that there was no significant difference in the results of the estimation formula at the level of $p<0.05$. Therefore, the estimation formula was valid and reliable.

Since all motions require the performance of several consecutive motions, the development of clothes should be taken into consideration for joint use for a specific motion rather than considering all motions for ease of measurement and accuracy. However, in order to obtain accurate motion suitability evaluation results for clothes jamming due to structures during boarding and entry, it is necessary to reproduce the hatch environment, which consists of a $2 \mathrm{~m}$ high deck with steps and a narrow passage that is $0.5 \mathrm{~m}$ wide. Nevertheless, the efficiency of clothing development can be improved even when only the general motion is considered, instead of evaluating the mission motion suitability of the tracked vehicle crew jacket.

\section{Conclusions}

In this paper, we proposed an estimation formula to predict mission motion suitability for the main mission of tracked vehicle crew members. The results of this study have important implications for the effectiveness of jacket evaluation for tracked vehicle crew members. The estimation formula for mission motion suitability was proposed using the 
five general motions commonly used in the evaluation of jackets, and this formula can be used instead of the mission motion protocol to save time and money. Furthermore, the findings of this study are worthwhile because motion suitability evaluation to develop an estimation formula was conducted on actual tracked vehicle crew members on active duty who performed the main mission on the actual tracked vehicle. However, the estimation formula for motion suitability evaluation is limited to jackets worn inside a tracked vehicle. Future studies should perform an additional analysis to evaluate different types of military uniforms for tracked vehicle crew members.

Author Contributions: Conceptualization, methodology, writing, H.-E.C.; investigation, data curation, validation, J.-I.J. Both authors have read and agreed to the published version of the manuscript.

Funding: This work was supported by the Defense Agency for Technology and Quality (DTaQ) grant funded by the Ministry of National Defense (No. 18-force support-01).

Institutional Review Board Statement: The study was conducted according to the guidelines of the Declaration of Helsinki, and approved by the Public Institutional Bioethics Committee designated by the Ministry of Health and Welfare (P01-201908-23-007, P01-202002-13-001).

Informed Consent Statement: Informed consent was obtained from all subjects involved in the study.

Data Availability Statement: Not applicable.

Conflicts of Interest: The authors declare no conflict of interest.

\section{References}

1. Evans, P.L. Protection of the crew of armoured fighting vehicles. Technical paper. AD0595605. In Chemical Defence Establishment; Porton Down: Salisbury, NC, USA, 1971.

2. Rahman, A.H.; Malik, A.S.; Kumar, J.R.; Balaguru, V.; Sivakumar, P. Design Configuration of a Generation Next Main Battle Tank for Future Combat. Def. Sci. J. 2017, 67, 343-353. [CrossRef]

3. Mao, M.; Xie, F.; Hu, J.-J.; Su, B. Analysis of workload of tank crew under the conditions of informatization. Def. Technol. 2014, 10, 17-21. [CrossRef]

4. K1/A1-main battle tank from South Korea developed by Rotem. Available online: https://www.army-technology.com/projects/ k1/ (accessed on 20 August 2021).

5. Parks, J.S. Main battle tank crew task analysis. Technical paper. ADA185784. In U.S. Army Tank Automotive Command; DTIC: Fort Belvoir, VA, USA, 1987.

6. Kim, E.W. A study on the technical aspects of, and the strategy for, the K1 series tank recapitalixation and the K2 tank product improvements. 2014 Korea. J. Assoc. Def. Ind. Stud. 2014, 21, 1-26.

7. Nissen, R.; Guldager, B.; Gyntelberg, F. Musculoskeletal Disorders in Main Battle Tank Personnel. Mil. Med. 2009, 174, 952-957. [CrossRef] [PubMed]

8. Sinha, P.K.; Pal, M.; Chandel, S. Ergonomics analysis of gunner station of armoured combat vehicle (ACV)- Tank T 90S with special reference to seat, visual sighting system and musculoskeletal discomfort: A pilot study. Asian J. Med Sci. 2021, 12, 87-94. [CrossRef]

9. Kwon, S.-Y.; Choi, E.-M.; Lim, C.-G.; Shin, D.-W.; Kim, K.-P.; Kwon, O.-K.; Jeong, H.-M. A Study on Wearing Satisfaction and Thermal Properties of Jumper for Korean Military Tank Drivers. Fash. Text. Res. J. 2012, 14, 261-268. [CrossRef]

10. Kwon, S.-Y.; Lim, C.-G.; Shin, D.-W.; Jung, H.-M. A Study on the Actual Wearing Conditions of Korean Military Tank Driver's Clothing. Fash. Text. Res. J. 2011, 13, 582-589. [CrossRef]

11. Choi, H.E. Development of ergonomic jacket patterns for the Korean army's tracked vehicle crew. Ph.D. Thesis, Seoul National University, Seoul, Korea, 2020. Unpublished.

12. Choi, H.E.; Choi, K.-M. Development and Evaluation of the Korean Army's Ergonomic Flight Jacket. Fash. Text. Res. J. 2021, 23, 118-128. [CrossRef]

13. Han, H.; Han, H. Development of Ergonomic Korean Male Military Winter Jacket. J. Korean Soc. Cloth. Text. 2018, 42, 943-961. [CrossRef]

14. Jeong, M.A. Development of a Pattern for Military Winter Uniform Tops Considering Size and Motion Appropriateness. Master's Thesis, Seoul National University, Seoul, Korea, 2014. Unpublished.

15. Lee, J.H. Development of Evaluation Standards and a Pattern for Combat Uniforms According to Combat Training Motions. Ph.D. Thesis, Seoul National University, Seoul, Korea, 2012. Unpublished.

16. Lee, S.-J.; Choi, Y.-L.; Nam, Y.-J. Development and Evaluation of Air Force Mechanic Parka to Enhance the Functions and Insulation. Fash. Text. Res. J. 2012, 14, 294-303. [CrossRef]

17. Huck, J. Protective clothing systems: A technique for evaluating restriction of wearer mobility. Appl. Ergon. 1988, 19, 185-190. [CrossRef] 
18. Damon, A.; Stoudt, H.W.; McFarland, R.A. The Human Body in Equipment Design; Harvard University Press: Cambridge, MA, USA, 1966. [CrossRef]

19. Kapandji, I.A. Physiologie Articulaire, 5th ed.; Youngmoon Press: Soeul, Korea, 2001.

20. Kim, S.; Lee, J.-Y. Development of Firefighting Performance Test Drills while Wearing Personal Protective Equipment. Fire Sci. Eng. 2016, 30, 138-148. [CrossRef]

21. Lee, H.H.; Shin, S.R.; Kim, Y.B.; Park, S.J.; Lee, J.Y. Evaluation of Mobility and Physiological Performance while Wearing the Present Korean Navy Summer Uniform and Prototype. J. Korean Soc. Living Environ. Syst. 2016, 23, 853-867. [CrossRef]

22. Kim, S.-K.; Choi, S.-G.; Hong, S.-C. A Study on the Activity and Training Plan of a Field Crew for the Design of Training Scenarios Assuming Chemical Accidents and Terrorism. Fire Sci. Eng. 2020, 34, 72-85. [CrossRef] 